\title{
Lights, camera and action in the implementation of central venous catheter dressing ${ }^{1}$
}

\author{
Maria Verônica Ferrareze Ferreira² \\ Simone de Godoy ${ }^{3}$ \\ Fernanda dos Santos Nogueira de Góes ${ }^{3}$ \\ Fernanda de Paula Rossini ${ }^{4}$ \\ Denise de Andrade ${ }^{5}$
}

Objective: to develop and validate an educational digital video on changing the dressing of shortterm, non-cuffed, non-tunneled central venous catheters in hospitalized adult patients. Method: this is a descriptive, methodological study based on Paulo Freire's assumptions. The development of the script and video storyboard were based on scientific evidence, on the researchers' experience, and that of nurse experts, as well as on a virtual learning environment. Results: the items related to the script were approved by $97.2 \%$ of the nurses and the video was approved by 96.1\%. Conclusion: the educational instrument was considered to be appropriate and we believe it will contribute to professional training in the nursing field, the updating of human resources, focusing on the educational process, including distance education. We believe it will consequently improve the quality of care provided to patients with central venous catheters.

Descriptors: Central Venous Catheters; Cross Infection; Health Education; Health Evaluation; Educational Technology; Nursing Care.

\footnotetext{
1 Paper extracted from doctoral dissertation "Dressing of central venous catheters: supports for nursing teaching and care", presented to Escola de Enfermagem de Ribeirão Preto, Universidade de São Paulo, PAHO/WHO Collaborating Centre for Nursing Research Development, Ribeirão Preto, SP, Brazil.

2 PhD, Laboratory Specialist, Escola de Enfermagem de Ribeirão Preto, Universidade de São Paulo, PAHO/WHO Collaborating Centre for Nursing Research Development, Ribeirão Preto, SP, Brazil.

${ }^{3}$ PhD, Professor, Escola de Enfermagem de Ribeirão Preto, Universidade de São Paulo, PAHO/WHO Collaborating Centre for Nursing Research Development, Ribeirão Preto, SP, Brazil.

${ }^{4}$ PhD, RN, Hospital das Clínicas, Faculdade de Medicina de Ribeirão Preto, Universidade de São Paulo, Ribeirão Preto, SP, Brazil.

${ }_{5}^{5} \mathrm{PhD}$, Associate Professor, Escola de Enfermagem de Ribeirão Preto, Universidade de São Paulo, PAHO/WHO Collaborating Centre for Nursing Research Development, Ribeirão Preto, SP, Brazil.
}

Corresponding Author:

Maria Verônica Ferrareze Ferreira

Universidade de São Paulo. Escola de Enfermagem de Ribeirão Preto

Av. Bandeirantes, 3900

Bairro: Monte Alegre

CEP: 14040-902, Ribeirão Preto, SP, Brasi

E-mail: mveronica@eerp.usp.br
Copyright () 2015 Revista Latino-Americana de Enfermagem This is an Open Access article distributed under the terms of the Creative Commons Attribution Non-Commercial License (CC BY-NC).

This license lets others distribute, remix, tweak, and build upon your work non-commercially, and although their new works must also acknowledge you and be non-commercial, they don't have to license their derivative works on the same terms. 


\section{Introduction}

Catheter-related infection, especially catheterrelated bloodstream infection (CRBI), is a concern given its severity and lethal nature. It presents a complex and multi-factor etiology. Studies show that the main determinants include: the patient's clinical condition, type and composition of the catheter, insertion technique, site, type of dressing, frequency with which the system is manipulated, and duration of catheter placement ${ }^{(1-3)}$.

It is worth noting that there is considerable interest among researchers, professionals and health facilities in reducing the incidence of catheter-related infections to improve the quality and safety of care provided to patients. Such efforts should be multidisciplinary and focus on patient behavior and adherence to recommendations during the insertion and handling of catheters, epidemiological surveillance of infections, and assessment of results ${ }^{(2,4)}$.

Even though there is no consensus regarding the best approach to reduce this type of infection, researchers suggest that training programs and the qualification of health providers effectively contribute to reducing infection rates $^{(1-4)}$.

In this sense, the teaching process should ground the development and support of healthcare training, aggregating values, knowledge and experiences. Educational actions refer to teaching-learning practices designed to challenge and promote knowledge to support clinical decision-making based on critical reflection on the profession's ethical and legal aspects.

The use of Freire's theory is justified due to the principles of dialogue, as a living exercise of dialogue: transitive consciousness, from naïve to critical; criticalreflective pedagogy; and transformation-action(5).

Due to a variety of teaching strategies, informatics increasingly gains relevance as an essential teaching tool. Hence, technological resources applied to nursing informatics are an essential basis for rapid access to information and both the construction and updating of knowledge. Specifically considering the field of nursing, many professionals have invested in the production of educational tools to facilitate teaching. These educational tools are generally known as hypermedia and consist of a combination of various media resources (e.g., texts, pictures, animation, and videos, among others), with the single purpose of education ${ }^{(6-9)}$.

Currently, educational videos are largely used to encourage and support the understanding of students in various contexts: classrooms, laboratories, and distance learning. Note that technologically advanced European universities have largely used videos since $1990^{(10-11)}$.

Given the previous discussion, we opted to developed a learning objective to lead users to reflect and act on, and consequently, transform the context of healthcare. Hence, this study's aim was to develop and validate an educational digital video that approaches the dressing of short-term, non-cuffed, non-tunneled central venous catheters in hospitalized adult patients.

\section{Method}

The objective of this descriptive methodological study was to develop a reliable, precise, and useable instrument to be employed in other studies(12).

Its methodological process was based on Paulo Freire's theory. A script was validated before the video was developed, as previously done by other researchers. An instrument, a storyboard with detailed description of the content to be included, was also developed in which the scenes and audio were established. The instruments to validate the script and video were previously submitted to apparent and content validation ${ }^{(6,9,13-14)}$.

Preexisting and well-established theoretical principles were used in the development of the aforementioned material(2,15). In addition to organizing content related to the topic in a logical manner, we also studied the scenario, the material and other resources to specify the details of narration, photos, figures and scenes involved in the filming.

Experts selected according to pre-established criteria validated the script ${ }^{(16)}$. The selection of experts to validate the video took into account the professionals' theoretical knowledge, competencies, and practical skills in performing dressings for CVCs. Hence, the following inclusion criteria were used: being a nurse working on a Hospital Infection Control Committee or providing care to patients with CVC, as well as teaching in undergraduate nursing programs, and having a Master's degree.

The experts were instructed in regard to the completing the validation instrument and invited to classify each item assessed as "strongly agree, agree, disagree, strongly disagree, or I do not know", not choosing more than one answer. Comments were welcomed.

The video was filmed in the Nursing Practice Simulation Center, University of São Paulo at Ribeirão Preto, College of Nursing (EERP-USP), between June and November, 2012. 
To facilitate the validation of the script and educational video, and because there was a support platform and management of the program in the teaching institution where the video was developed, the material and an informed consent form was included in a virtual learning environment on the Internet, Stoa. Twelve experts validated the script and 13 experts validated the video. All the participants signed free and informed consent forms.

\section{Results}

\section{Script validation}

The instrument used to validate the script of the educational video was composed of six questions addressing the video's objective, content, relevance, environment, verbal language and inclusion of topics.

The answers "strongly disagree" and "I do not know" were not chosen for any of the questions. Hence, all the items were considered appropriate, as the sum of the options "strongly agree" and "agree" was above $97.2 \%$. Agreement of $100 \%$ was achieved in the questions addressing relevance, environment and verbal language.

In regard to the assessment of objectives, there was a report that the script was very interesting. In regard to the only case in which one expert answered "disagree" to a question, he suggested the inclusion of the topic manipulation of CVCs in the educational video because it is an extremely important factor in the acquisition of bloodstream infections.

In the question concerning content, one of the experts indicated that it would be interesting to film the dressing being applied on a real hospitalized patient. There was also a recommendation to provide a detailed description of how to apply and remove dressings used on the site where a CVC is inserted, as well as in regard to site cleanup. One nurse suggested asking the patient to turn his/her head away when the dressing is being applied. In regard to patient position, one expert indicated the need to complement the comment "if there is no counter-indication". The need to perform hand hygiene after removing gloves worn during removal of the CVC coverage was stressed and alcohol gel was indicated. In regard to the item related to the material used in CVC dressings, a suggestion was to replace the antiseptic liquid soap by common liquid soap for hand washing. There was also a recommendation to use surgical masks while performing the procedure.
In regard to the relevance of images and scenes present in the video script, the suggestions included the possibility of performing the dressing on a real patient in a hospital setting.

For the environment, one nurse suggested adding some items in the movie set to make it better resemble a hospital ward.

In regard to verbal language, some experts recommended avoiding long sentences to facilitate the narration and also to establish well-defined pauses.

The question that addressed the inclusion of topics obtained one "disagree" response and one expert suggested using PVPI alcohol to perform the antisepsis of the CVC insertion site only when the patient is allergic to the $0.5 \%$ chlorhexidine solution, advising against the use of alcohol at $70 \%$ due to its low residual effect.

\section{Educational video recording}

One 12 minute and 10 second educational video addressing CVC dressing change was developed, which contained the following: video objectives, brief history of CVC, purpose of CVC, objectives of changing CVC dressing, and description of the stages of CVC dressing change.

The video included photos, animation, scenes, and descriptive slides. The photo shoot was initiated with the material used in the dressing procedure and with some scenes according to the script previously developed. Most images were captured in the laboratory at EERP-USP with a digital Canon photographic camera, model EOS7D. The treatment and sequence of photos were performed by the researcher together with an audiovisual professional from the Multimedia Production and Creation Service (SVCPM) at EERP-USP, using Adobe Photoshop CS6. The animation was also performed by this professional and was based on photos from books using Adobe Flash CS6.

The scenes were filmed by SVCPM and were repeated several times to find the best situation that reflected the script content. Two Sony digital camcorders, model HDR CX190, were used. A broadcast journalist narrated the video. The video editing was performed with Adobe Premiere CS6 and took approximately 60 hours.

\section{Educational video validation}

The instrument to validate the educational video was composed of six questions addressing its functionality, usability, efficiency, audiovisual technique, environment, and procedure. 
The answer "strongly disagree" was not chosen for any of the questions. All the items were considered appropriate, as the sum of the answers "strongly agree" and " agree" was greater than 96.1\%. 100\% agreement was achieved in regard to the questions concerning functionality, usability and efficiency.

In regard to item functionality, one expert observed that the video is up to date and is in agreement with current scientific guidelines.

In regard to the question related to usability, the images were praised as being clear and didactic and that the professional applying the dressing presented excellent posture and ability performing the procedure.

In terms of efficiency, one expert considered the duration of the video, at approximately 12 minutes, to be too long, especially for undergraduate nursing students, arguing students could lose their attention.

In regard to the audiovisual technique, one expert noted the background music was too loud, which could divert attention from the scenes and lead to viewers becoming unquiet. There was also a suggestion for prolonging the pauses in the narration in some points.

There was a "disagree" response to the question regarding the environment. One nurse noted that laboratory surroundings are different from daily clinical practice because there is a larger number of people in a hospital setting, more apparatus and equipment, which is different from the space and scenario shown in the video, while some experts praised the simulation center where the video was filmed and the fact the researcher hid the labels of the products used.

There was disagreement in regard to two items concerning the procedure. One of the experts considered it irrelevant to address the possibility of pulling out the catheter and protective dressing during showering. In this item, however, one of the experts was of the opinion that the video was perfect.

\section{Discussion}

It is important to note that all the experts' suggestions during the script and video validation were very important and exhaustively discussed. Some of them are presented here.

The topic concerning CVC manipulation was not addressed in this video because the study's focus was CVC dressing change as performed by nurses.

Various experts suggested the video be filmed in a real situation, that is, with a hospitalized patient.
In this regard, clinical simulation is highlighted in the literature as a strategy to develop critical thinking, as well as promoting increased skills in assessment and clinical decision-making that is required during clinical practice(17-18). The use of simulated dressing in laboratory in this study is designed to replicate real and essential aspects of real clinical practice, however, with the convenience being able to repeat content, information and actions as many times as necessary in a safe and controlled environment. Additionally, we sought to ensure the safety of patients, reducing errors during procedures. We also considered the number of professionals in a technical and support staff required to produce the video, in addition to equipment, noise, and conversation that would expose patients and workers from a hospital ward to inconvenient situations. Therefore, we adopted the assumptions of various researchers emphasizing and recommending that simulations be performed in protected spaces in order to avoid exposing patients to errors ${ }^{(19-20)}$.

In regard to the suggestion of one expert to use sterile surgical masks while changing dressings, we note that scientific evidence concerning this topic is inconclusive, especially due to a lack of studies showing its efficacy ${ }^{(21)}$. Therefore, we opted not to use masks.

In regard to the recommendation of one expert for the use of PVPI alcohol for the antisepsis of the CVC insertion site only in cases when the patient is allergic to chlorhexidine at $0.5 \%$, we opted to leave its use optional along with the optional use of alcohol. It is worth noting that iodine products present a broad activity against gram-positive and -negative bacteria, tubercle bacilli, fungi and viruses and are somewhat active against spores. In regard to the low residual effect of alcohol, note that alcohol has rapid anti-microbial action when applied to skin and, even though it does not present considerable residual activity, microbial re-colonization occurs only slowly after its use. Also, despite the fact it does not act against sporulated forms, in appropriate concentrations, it is considered a low-cost, extremely fast and efficacious antiseptic to reduce the number of microorganisms present on skin. Additionally, it is among the safest antiseptics, not only because of its low toxicity, but also because it is easy to apply and has rapid anti-microbial effect(22). It is worth noting that studies recommend the use of iodine tincture or alcohol at $70 \%$ for skin antisepsis during CVC dressing if there is counter indication to chlorhexidine ${ }^{(2,21)}$.

In regard to the video's duration, researchers recommend that this type of teaching strategy does 
not exceed 15 minutes of duration, while others argue that videos of approximately 10 minutes duration more easily hold the attention of viewers ${ }^{(14,23)}$. Researchers developed an educational video addressing puncture and heparinization of totally implanted CVCs, the objective of which was to assess the effect of the video on the development of cognitive and technical competencies of undergraduate nursing students. The objectives were achieved with a video of 13 minutes and 47 seconds duration $^{(13)}$. Therefore, the final version of the video developed in this study is in accordance with scientific literature addressing this subject.

We consider the reproduction of a real environment using material and equipment identical to that used in clinical practice enabled composing a scenario with characteristics that are close to reality. Hence, we believe this activity was possible in this situation.

It is important to note that the admonition to remove CVC if it accidentally disconnects was kept in the video because it is a situation that may happen and should be verified, especially when replacing dressings. Additionally, there is scientific evidence showing the need to stabilize intravenous catheters, mainly to reduce migration or dislocation, in order to prevent catheterrelated bloodstream infections (CRBSI) ${ }^{(2,21)}$.

The part related to protecting the dressing during shower was also preserved. In this context, researchers emphasize that CVCs and the insertion site should not become wet, so that waterproof coverage should be used to prevent moisture, and consequently, contaminants from entering the catheter and infusion lines ${ }^{(2)}$.

\section{Conclusion}

It is the consensus that teaching methods have experienced transformations to meet the needs of a society in continuous change and development. From this perspective, the investment in technologies to be used in teaching-learning strategies seeking to develop and improve competencies that are required in clinical practice has been largely disseminated.

Given the objectives proposed, the conclusion is that the educational video was validated and is appropriate to be made available. We expect it to contribute to the professional qualification of nurses and other healthcare providers as it approximates students to a clinical situation they have not yet experienced. This instrument will also enable not only the improvement of cognitive and technical skills related to the procedure, but will also facilitate the educational process, including distance learning, resulting in the improvement of the quality of care.

\section{References}

1. Wilson C. Preventing central venous catheter-related bloodstream infection. Nurs Stand. 2015;29(19):37-43. 2. O'Grady NP, Alexander M, Burns LA, Dellinger EP, Garland J, Heard SO, et al. Guidelines for the prevention of intravascular catheter-related infections. Clin Infect Dis. 2011;52(9):e162-e93.

3. Zingg W, Walder B, Pittet D. Prevention of catheterrelated infection: toward zero risk? Curr Opin Infect Dis. $2011 ; 24(4): 377-84$.

4. Scatliffe K, Adebanke D, Wang-Kocik C, Villanueva NM, Espiritu-fuller M, Larang $R$, et al. The reduction of catheter-related bloodstream infections through the implementation of an interdisciplinary healthcare team. J Crit Care Med. [Internet]. 2015; [Acesso 25 mai 2015]; 2015. Disponível em: http://www.hindawi.com/ journals/jccm/2015/635939/cta/

5. Freire P. Pedagogia do oprimido. 29. ed. São Paulo: Paz e Terra; 2000. 96 p.

6. Barbosa RCM, Pinheiro AKB. Validação de um vídeo educativo para promoção do apego entre mãe soropositiva para HIV e seu filho. Rev Bras Enferm. $2011 ; 64(2): 328-34$.

7. Ferecini GM, Góes FSN, Fonseca LMM, Leite AM, Scochi CGS. Avaliação de um website sobre o aleitamento materno do prematuro. Cienc Cuid Saúde. 2012;11(4):642-9.

8. Góes FSN, Fonseca LMM, Furtado MCC, Leite AM, Scochi CGS. Evaluation of the virtual learning object "Diagnostic reasoning in nursing applied to preterm newborns". Rev. Latino-Am. Enfermagem. [Internet]. 2011 [Acesso 21 mai 2015];19(4):894901. Disponível em: http://www.scielo.br/pdf/rlae/ v19n4/pt_07.pdf.

9. López ML, Carvalho EC. The therapeutic communication during installation of endovenous therapy: the use of video-taped simulation. Rev. Latino-Am. Enfermagem. [Internet]. 2006;14(5):658-65. [Acesso 21 mai 2015]; Disponível em: http://www.scielo.br/pdf/rlae/v14n5/ pt_v14n5a04.pdf.

10. Barford J, Weston $C$. The use of video as a teaching resource in a new university. $\mathrm{Br} J$ Educ Technol. 1997;28(1):40-50.

11. Salina L, Ruffinengo C, Garrino L, Massariello P, Charrier L, Martin B, et al. Effectiveness of an educational video as an instrument to refresh and reinforce the 
learning of a nursing technique: a randomized controlled trial. Perspect Med Educ. 2012;1(2):67-75.

12. Polit DF, Beck CT. Fundamentos de pesquisa em enfermagem: avaliação de evidências para a prática da enfermagem. 7ed. Porto Alegre: Artmed; 2011. p. 163-98. 13. Cardoso AF, Moreli L, Braga FTMM, Vasques CI, Santos $\mathrm{CB}$, Carvalho EC. Effect of a video on developing skills in undergraduate nursing students for the management of totally implantable central venous access ports. Nurse Educ Today. 2012;32(6):709-13.

14. Fleming SE, Reynolds J, Wallace B. Lights... câmera... action! A guide for creating a DVD/Video. Nurse Educ. 2009;34(3):118-21.

15. Mermel LA, Allon M, Bouza E, Craven DE, Flynn $P$, O'Grady NP, et al. Clinical practice guidelines for the diagnosis and management of intravascular catheterrelated infection: 2009 update by the Infectious Diseases Society of America. Clin Infect Dis. 2009; 49(1):1-45.

16. Fehring RJ. Methods to validate nursing diagnoses. Heart Lung. 1987;16(6):625-29.

17. Dillard N, Sideras S, Ryan M, Carlton K, Lasater K, Siktberg L. A collaborative project to apply and evaluate the clinical judgment model through simulation. Nurs Educ Perspect. 2009;30(2):99-104.

18. Teixeira INDO, Felix JVC. Simulação como estratégia de ensino em enfermagem: revisão de literatura. Interface (Botucatu). 2011;15(39):1173-84.

19. Santos MC, Leite MCL. A avaliação das aprendizagens na prática da simulação em enfermagem como feedback de ensino. Rev Gaucha Enferm. 2010;31(3):552-6.

20. Teixeira CRS, Kusumota L, Braga FTMM, Gaioso VP, Santos CB, Silva VLS, et al. O uso de simulador no ensino de avaliação clínica em enfermagem. Texto Contexto Enferm. 2011;20(Esp):187-93.

21. Infusion Nurses Society (INS). Infusion nursing standards of practice. J Infus Nurs. 2011;34(1):1-110. Supplement.

22. Graziano MU, Graziano KU, Pinto FMG, Bruna CQM, Queiroz RQ, Lascala CA. Effectiveness of disinfection with alcohol $70 \%(\mathrm{w} / \mathrm{v})$ of contaminated surfaces not previously cleaned. Rev. Latino-Am. Enfermagem. [Internet]. 2013 [Acesso 21 mai 2015]; 21(2):618-23. Disponível em: http://www.scielo.br/pdf/rlae/v21n2/ pt_0104-1169-rlae-21-02-0618.pdf.

23. Hartsell T, Yuen S. Video streaming in online learning. AACEJ. 2006;14(1):31-43. 